(C) 2007 The Japan Society of Applied Physics

\title{
Complete Decomposition of Benzene, Toluene, and Particulate Matter Contained in the Exhaust of Diesel Engines by Means of Thermally Excited Holes in Titanium Dioxide at High Temperatures
}

\author{
Takashi Makino, Keiji Matsumoto, Toru Ebara, Takashi Mine, Takumi OhtsukA, and Jin Mizuguchi \\ Department of Applied Physics, Graduate School of Engineering, Yokohama National University, Yokohama 240-8501, Japan
}

(Received April 17, 2007; accepted May 22, 2007; published online September 7, 2007)

We previously reported on a decomposition system of organic wastes by the use of thermally excited holes in $\mathrm{TiO}_{2}$ at high temperatures. A good feature of our system is that it makes use of a large number of holes formed, for example, at $350{ }^{\circ} \mathrm{C}$ for the oxidation of organic wastes. In this investigation, we aim at applying this technology to the complete decomposition of benzene, toluene, and particulate matter (PM) included in the exhaust of diesel engines. Special attention has been paid to the adsorption process of benzene and toluene onto the surface of $\mathrm{TiO}_{2}$, as well as to their subsequent decomposition, as studied by thermal analysis, Raman spectroscopy, and ESR in consideration of the specific surface of $\mathrm{TiO}_{2}$ powders. Both benzene and toluene are found to completely decompose into $\mathrm{H}_{2} \mathrm{O}$ and $\mathrm{CO}_{2}$ at about $350{ }^{\circ} \mathrm{C}$, via fragments of ethylene, butene, propene, and butadiene. On the other hand, PM appears more difficult to decompose due to its powdered form. However, PM was finally confirmed to be decomposed when the mixture of $\mathrm{PM}$ and $\mathrm{TiO}_{2}$ was heated under a pressure of about $280 \mathrm{~N} / \mathrm{m}^{2}$ at about $350^{\circ} \mathrm{C}$. [DOI: $10.1143 / \mathrm{JJAP} .46 .6037$ ]

KEYWORDS: titanium dioxide, thermal excitation, oxide semiconductor, exhaust, diesel engine

\section{Introduction}

We have previously reported on a complete decomposition system of polycarbonates (PC; used as substrates for optical disks) that utilizes thermally excited holes in $\mathrm{TiO}_{2}$ at high temperatures. ${ }^{1-3)}$ The above investigation has been initiated in view of the serious problem on how to dispose used optical disks. Our decomposition system is similar to the photocatalytic system that makes use of photogenerated holes for the oxidation decomposition of various substances. However, our system differs distinctly in the utilization of thermally excited holes at high temperatures (for example, at about $350^{\circ} \mathrm{C}$ ) in combination with a molten state of PC, as shown in Fig. 1. A large number of charge carriers are available in $\mathrm{TiO}_{2}$ at high temperatures as shown by the product of the Fermi-Dirac distribution function and the density of states. ${ }^{4)}$ The number of carriers at room temperature $(\mathrm{RT})$ and $350^{\circ} \mathrm{C} \quad\left[n_{\mathrm{RT}}=n_{0} \exp \left(-E_{\mathrm{g}} / 2 k T_{\mathrm{RT}}\right)\right.$ and $n_{623 \mathrm{~K}}=n_{0} \exp \left(-E_{\mathrm{g}} / 2 k T_{623}\right)$, respectively] gives a ratio of $n_{623 \mathrm{~K}} / n_{\mathrm{RT}} \approx 8.8 \times 10^{13}$, where $E_{\mathrm{g}}=3.2 \mathrm{eV}$. This number has approximately been confirmed in our previous experiment based on the single crystals of $\mathrm{TiO}_{2}$ of the rutile phase. ${ }^{3)}$ In addition, PC melts into liquid at these temperatures to form the "solid $\left(\mathrm{TiO}_{2}\right)$ /liquid (molten PC)" interface. This enables us to successively decompose PC into small fragments, followed by complete combustion with oxygen to yield solely $\mathrm{H}_{2} \mathrm{O}$ and $\mathrm{CO}_{2}{ }^{2}{ }^{2)}$ To date, we have shown that all kinds of thermoplastic resins and thermosetting polymers (i.e., three-dimensional polymers that have no melting point) can completely be decomposed. ${ }^{3)}$ We have also confirmed that any types of semiconductors can basically work as an alternative for $\mathrm{TiO}_{2}$ if they are stable in air at high temperatures. ${ }^{3)}$ Among these, however, $\mathrm{TiO}_{2}$ is still the best material at present. The mechanism of decomposition has also been clarified to proceed in such a way that radicals are initially formed in PC by thermally generated holes and then propagate throughout the material to break up PC into fragments, ending up with their complete combustion with oxygen to yield $\mathrm{H}_{2} \mathrm{O}$ and $\mathrm{CO}_{2}$ (Fig. 1). ${ }^{3)}$ These results prompted us to believe that even benzene, toluene, and particulate matter (PM) included in the exhaust of diesel engines can be decomposed by this technology. Diesel engines have been widely used for trucks, passenger cars, vessels, heavy machineries, and so on. Diesel engines are characterized by various factors such as a high thermal efficiency of about $45-50 \%$, which is higher than that in gasoline engines by about $10-15 \%$, as well as high torque, robustness, and low fuel consumption among others. On the other hand, the main drawback of diesel engines lies in their exhaust comprising mainly hydrocarbons (benzene, toluene, etc.), PM, and $\mathrm{NO}_{x}$. $\mathrm{PM}$ is a carbonlike, black powder comprising aromatic and aliphatic hydrocarbons and sulfates. In this study, we focus on the complete decomposition of benzene, toluene, and PM.

\section{Experiment}

\subsection{Materials}

$\mathrm{TiO}_{2}$ powders of ST01 (anatase form) and CR80 (rutile form) were obtained from Ishihara Sangyo (ISK). ST01 is an active $\mathrm{TiO}_{2}$ and it is designed for photocatalysts with a specific surface of about $278 \mathrm{~m}^{2} / \mathrm{g}$ and a grain size of about $7 \mathrm{~nm}$. On the other hand, CR80 is a surface-coated $\mathrm{TiO}_{2}$ used widely as a white pigment and as an inert reference in this investigation together with $\alpha-\mathrm{Al}_{2} \mathrm{O}_{3}$ (Junsei Chemical). All powdered samples were calcinated in air at $500{ }^{\circ} \mathrm{C}$ for $1 \mathrm{~h}$ before use. Due to this calcinations, the specific surface of ST-01 was decreased from 278 to $96 \mathrm{~m}^{2} / \mathrm{g}$; however, it remains nearly unchanged with further calcination. On the other hand, no noticeable change was recognized in CR80 and $\alpha-\mathrm{Al}_{2} \mathrm{O}_{3}$. Benzene and toluene of GR grade were purchased from Wako Pure Chemical Industries. PM powders were supplied by ISUZU Advanced Engineering Center.

\subsection{Autoclave used for decomposition of benzene and toluene}

An autoclave equipped with a mass spectrometer was particularly designed for this experiment. The schematic representation is show in Fig. 2. The volume of the reaction vessel is $300 \mathrm{ml}$, in which $40 \mathrm{~g}$ of $\mathrm{TiO}_{2}$, or CR80 or $\alpha-\mathrm{Al}_{2} \mathrm{O}_{3}$ was charged. The stirrer rotates at a rate of $150 \mathrm{rpm}$. Gases 


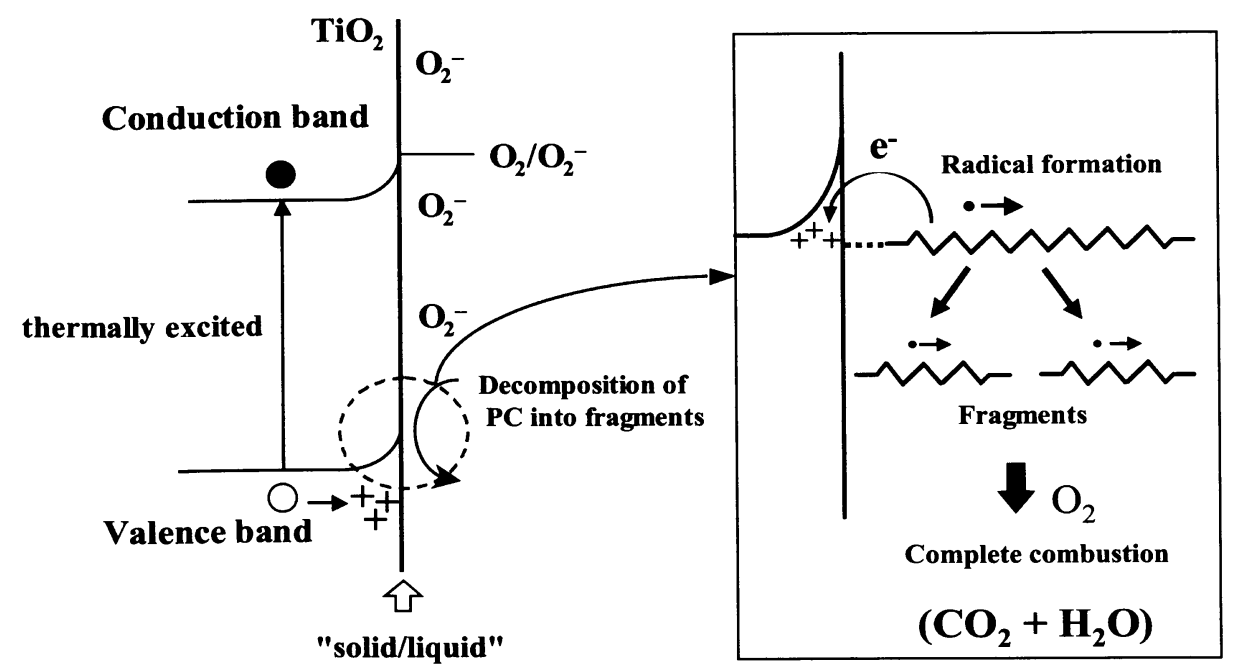

Fig. 1. Decomposition of $\mathrm{PC}$ at " $\mathrm{TiO}_{2} / \mathrm{PC}$ " interface by thermally generated holes.

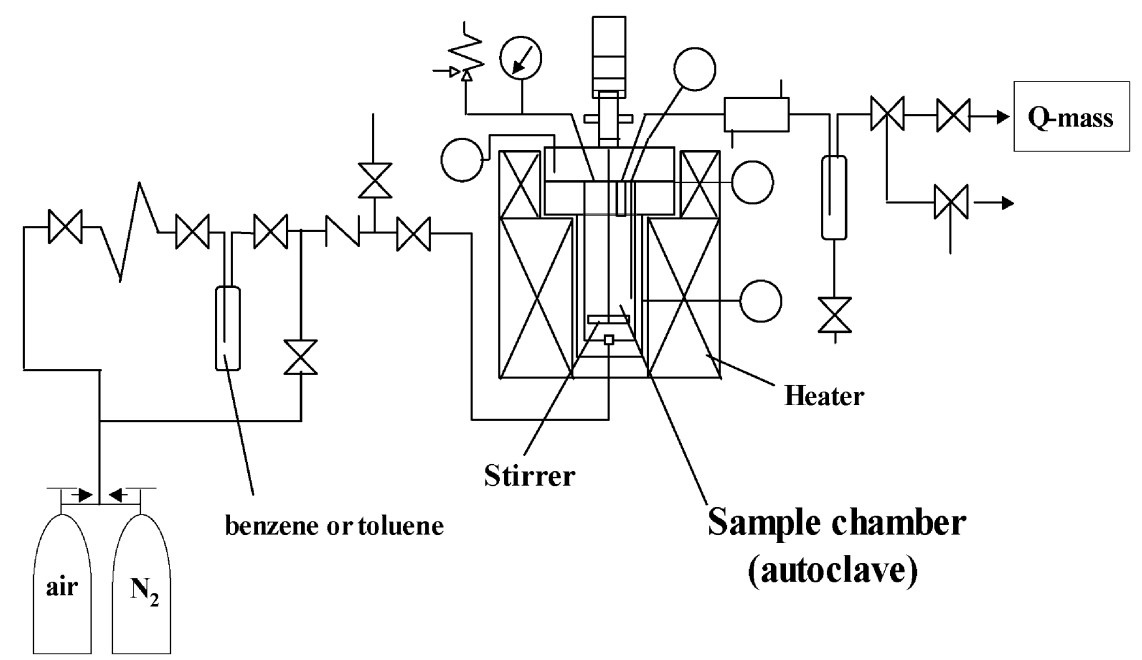

Fig. 2. Schematic representation of autoclave used for decomposition experiments. Q-mass denotes a quadrupole mass spectrometer.

(benzene or toluene) were introduced, using air or $\mathrm{N}_{2}$ as the carrier gas, into the reaction vessel from the bottom of the autoclave through a sintered filter of stainless steel powders. Benzene or toluene-saturated vapors were prepared by bubbling either air or $\mathrm{N}_{2}$. The concentrations of benzene and toluene were 3.03 and $2.28 \%$ relative to air, respectively. The gas flow rate was controlled at $200 \mathrm{ml} / \mathrm{min}$; whereas the temperature was varied in the range between 100 and $500{ }^{\circ} \mathrm{C}$. The outgas was sampled at various temperatures and analyzed by mass spectrometry.

\subsection{Sampling of the intermediate: benzene $/ \mathrm{TiO}_{2}$ and toluene $/ \mathrm{TiO}_{2}$}

To study the intermediates in the decomposition process, ca. $100 \mathrm{mg}$ of $\mathrm{TiO}_{2}$ powders was extracted from the reaction vessel every $50^{\circ} \mathrm{C}$ in situ in the temperature range from 100 to $500{ }^{\circ} \mathrm{C}$. These samples were brown and highly viscous due to reactions between the adsorbate (benzene or toluene) and the adsorbent $\left(\mathrm{TiO}_{2}\right)$, as described later in $\$ 3.2$.

\subsection{Decomposition of PM}

Two kinds of samples were prepared for the decomposition test. Sample 1 is a mixture of $1.0 \mathrm{mg}$ of PM (black powder) with $50 \mathrm{mg}$ of ST01 (white powder) ground in a mortar with a pestle. Sample 2 is a tablet prepared by pressing sample 1 with a pressure of $280 \mathrm{~N} / \mathrm{m}^{2}$. PM/CR80 samples were also prepared as reference with the same composition.

\subsection{Equipment for measurement}

DSC 8230 and TGA 8120 from RIGAKU were used for measurements of differential scanning calorimetry (DSC) and thermogravimetric analysis (TGA), respectively. The heating rate was $10^{\circ} \mathrm{C} / \mathrm{min}$ in both measurements. Raman spectra were measured using a NRS-3100 laser Raman spectrophotometer from JASCO. Measurements of electron spin resonance (ESR) were carried out using a JES-FA200 from JEOL. ESR signals were corrected by Mn markers and radical concentrations were estimated on the basis of the concentration of $\alpha, \alpha^{\prime}$-diphenyl- $\beta$-picryslhydrazyl (DPPH) used as the reference. A quadrupole mass spectrometer (model RG-102 from ULVAC) was used for gas analysis.

\section{Results and Discussion}

3.1 Decomposition of benzene or toluene in autoclave

Figure 3 shows the decomposition process of benzene on $\mathrm{TiO}_{2}$ in air as a function of temperature, as monitored by 


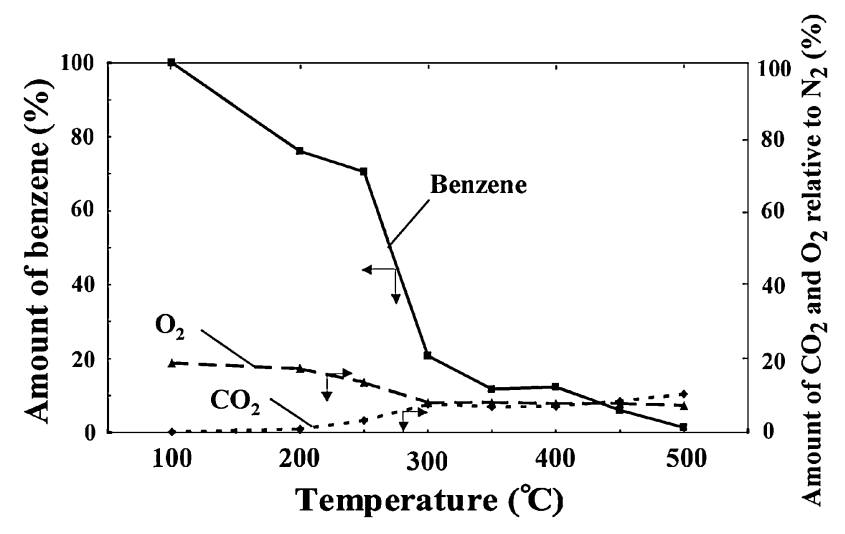

Fig. 3. Decomposition of benzene in air by ST01 as a function of temperature.
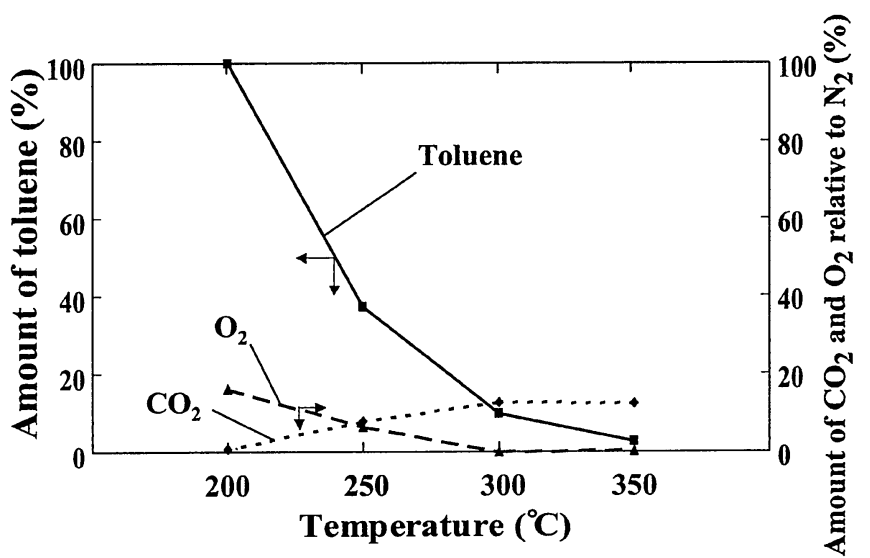

Fig. 4. Decomposition of toluene in air by means of ST01 as function of temperature.

a mass spectrometer. The amounts of $\mathrm{O}_{2}$ and $\mathrm{CO}_{2}$ are expressed relative to the amount of $\mathrm{N}_{2}$. Note that benzene starts to decompose even at $200{ }^{\circ} \mathrm{C}$ and completely decomposes at approximately $500{ }^{\circ} \mathrm{C}$, forming $\mathrm{CO}_{2}$ and $\mathrm{H}_{2} \mathrm{O}$ (not shown), whereas no other species were detected except for $\mathrm{N}_{2}$ and $\mathrm{O}_{2}$ in air. The $\mathrm{CO}_{2}$ concentration increases as the decomposition reaction of benzene proceeds, whereas the $\mathrm{O}_{2}$ concentration decreases because $\mathrm{O}_{2}$ is used up for the combustion of fragments derived from benzene. The decomposition of toluene is shown in Fig. 4. The process appears similar to that of benzene. However, the decomposition is completed at a lower temperature of about $350{ }^{\circ} \mathrm{C}$ than that of benzene. This is because toluene is a polar molecule due to an electron-donating methyl group. This facilitates the adsorption of toluene on $\mathrm{TiO}_{2}$ and its subsequent decomposition.

To study the role of oxygen in the decomposition of benzene, a comparison experiment was carried out in $\mathrm{N}_{2}$ (i.e., in the absence of $\mathrm{O}_{2}$ ) under the same conditions. As observed from Fig. 5, benzene remains undecomposed even at $500{ }^{\circ} \mathrm{C}$ and no change in $\mathrm{CO}_{2}$ concentration is recognized. This points out the importance of the presence of oxygen for decomposition. Then, another reference experiment was also carried out in air, using $\alpha-\mathrm{Al}_{2} \mathrm{O}_{3}$ in place of ST01. Figure 6 shows the decomposition as a function of temperature. Only a slight decomposition of benzene is recognized above $400{ }^{\circ} \mathrm{C}$, accompanied by a decrease and an increase in $\mathrm{O}_{2}$

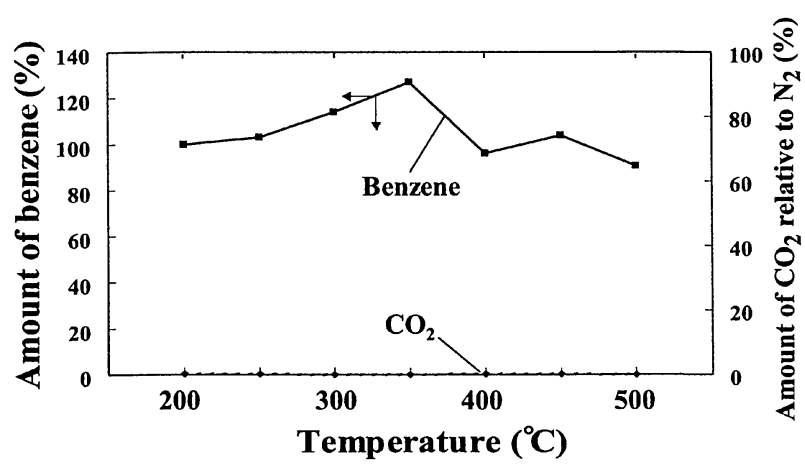

Fig. 5. Decomposition of benzene in $\mathrm{N}_{2}$ by means of ST01 as function of temperature.

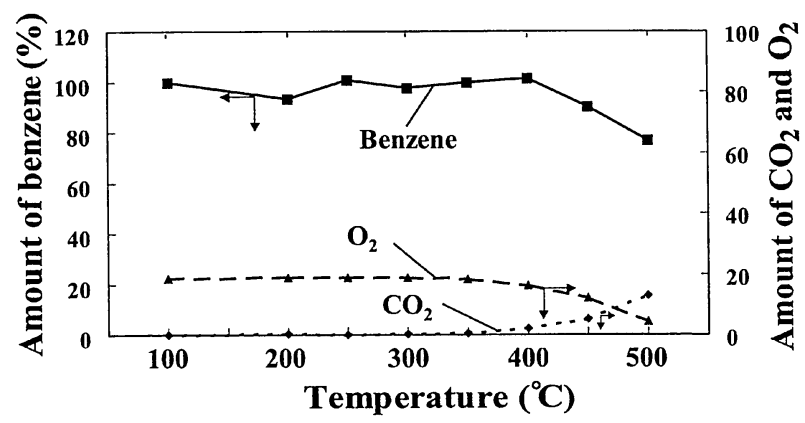

Fig. 6. Decomposition of benzene in air by $\alpha-\mathrm{Al}_{2} \mathrm{O}_{3}$ as function of temperature.

and $\mathrm{CO}_{2}$ concentrations, respectively. The above results indicate how powerful ST01 is for decomposition as compared with $\alpha-\mathrm{Al}_{2} \mathrm{O}_{3}$.

\subsection{Characterization of intermediates in decomposition of benzene and toluene}

The intermediate samples extracted from the reaction vessel during the decomposition (see $\$ 2.3$ ) in steps of $50{ }^{\circ} \mathrm{C}$ were characterized by DSC, ESR, Raman spectroscopy, and mass spectrometry.

ST01 is pure white and nonsticky powder. On the other hand, all "benzene/ST01" and "toluene/ST01" powders extracted were brown and highly sticky irrespective of the sampling temperature, although the extent of coloration was different. This clearly indicates that certain interactions took place between the adsorbent $\left(\mathrm{TiO}_{2}\right)$ and the adsorbate (benzene or toluene). Figure 7 shows the DSC curves of benzene/ST01 and toluene/ST01, both of which were sampled at $200^{\circ} \mathrm{C}$. The exothermic peaks appear at about 330 and $350^{\circ} \mathrm{C}$ for benzene/ST01 and toluene/ST01, respectively, indicating the decomposition of benezene and toluene in air. The exothermic peak of toluene/ST01 is present at a lower temperature than that of benzene/ST01 by about $20^{\circ} \mathrm{C}$. Furthermore, all intermediates sampled in the range between 100 and $300^{\circ} \mathrm{C}$ show similar DSC curves for both benzene/ST01 and toluene/ST01.

The Raman spectra of the samples used for the above DSC are shown in Fig. 8. In toluene/ST01, a peak shift of about $2 \mathrm{~cm}^{-1}$ is observed toward higher wavenumbers. On the other hand, no noticeable peak shift is recognized in benzene/ST01. Nevertheless, the background at higher 


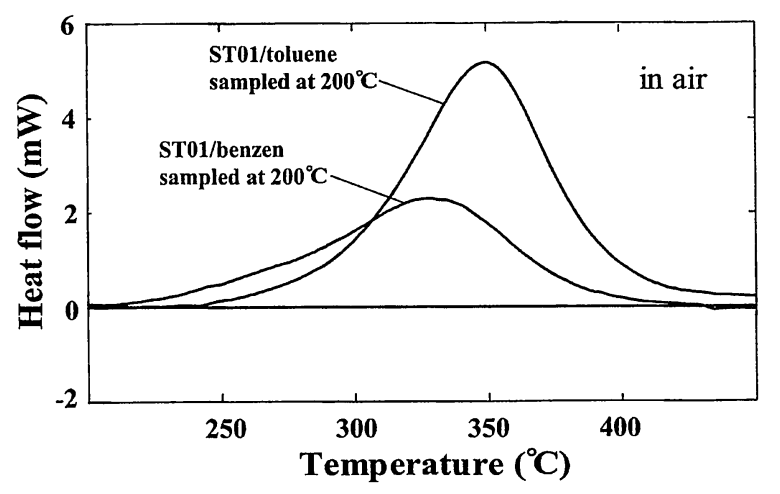

Fig. 7. DSC curves of benzene/ST01 and toluene/ST01 powders, both of which were sampled at $200^{\circ} \mathrm{C}$.

(a)

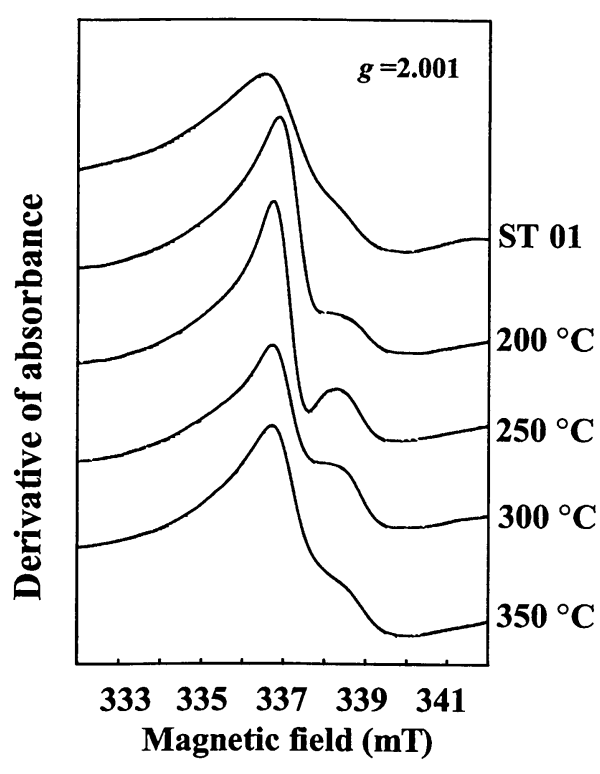

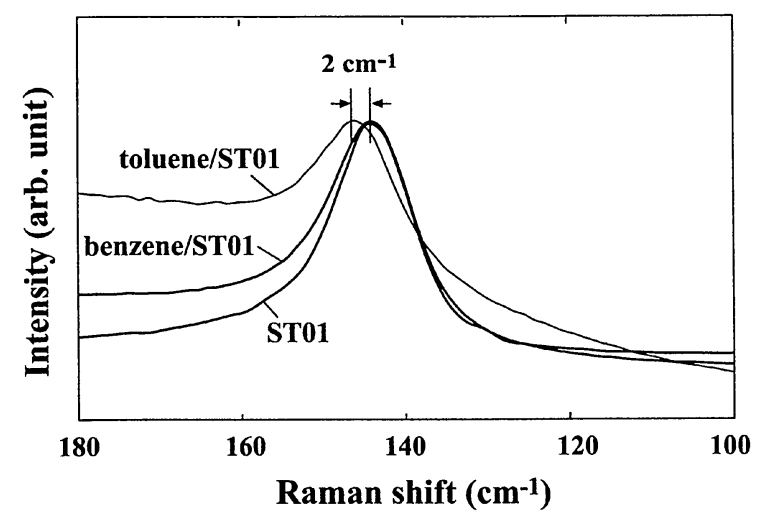

Fig. 8. Peak shifts of Raman spectra in benzene/ST01 and toluene/ST01 powders sampled at $200^{\circ} \mathrm{C}$.

(b)

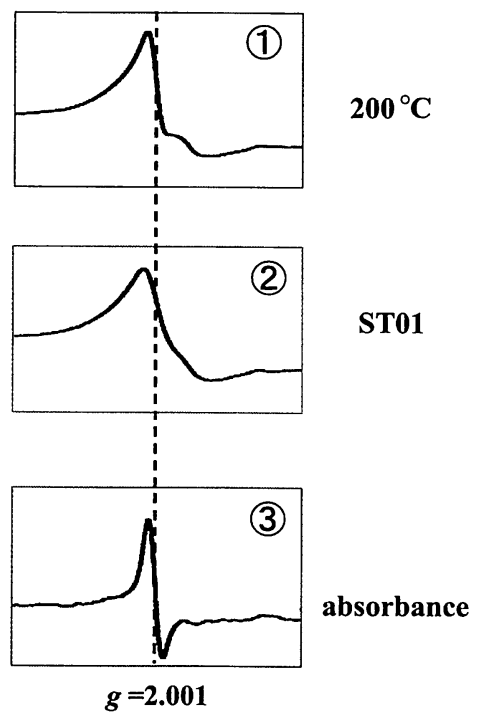

spectrum (3) $=$ spectrum(1) $-\operatorname{spectrum(2)}$

Fig. 9. (a) ESR spectra of benzene/ST01 powders sampled at various temperatures and (b) difference in spectrum as obtained by subtracting the signal of ST01 from that of benzene/ST01 sampled at $200{ }^{\circ} \mathrm{C}$.

wavenumbers is enhanced to increase, suggesting the adsorption of benzene on $\mathrm{TiO}_{2}$.

As described above, the intermediates (benzene/ST01 and toluene/ST01) were brown, but the extent of coloration varies, depending on the temperature. The brownish color intensified with increasing temperature and was deepest at $200-250{ }^{\circ} \mathrm{C}$ and then faded out gradually, ending up as white again at $350^{\circ} \mathrm{C}$. This color change is well correlated with the appearance and disappearance of ESR signals, as shown below. Since both toluene/ST01 and benzene/ST01 behaved nearly in the same way, only the latter result is shown below. Figure 9(a) shows the ESR spectra of ST01 and benzene/ST01 powders sampled at 200, 250, 300, and $350{ }^{\circ} \mathrm{C}$. One can observe a small shoulder (or a small peak) in all benzene/ST01 spectra at about $338.5 \mathrm{mT}$. This is ascribed to the ESR signal derived from the adsorbed benzene on $\mathrm{TiO}_{2}$, as shown by the difference in spectra shown in Fig. 9(b), where the ESR signal of ST01 is subtracted from that of the intermediate at $200{ }^{\circ} \mathrm{C}$. The shoulder signal becomes stronger with increasing temperature and becomes maximum at approximately $200-250^{\circ} \mathrm{C}$.
Then, it becomes again and disappears at approximately $350{ }^{\circ} \mathrm{C}$. The appearance and disappearance of both the ESR signal and the brownish color of the intermediates indicate the formation of the intermediate (benzene/ST01 or toluene/ST01) and its decomposition, respectively. Above $350{ }^{\circ} \mathrm{C}$, neither the ESR signal nor the brownish color can be recognized. However, this does not mean that benzene is not decomposed, but this does mean that benzene is immediately decomposed due to the increased number of holes above $350^{\circ} \mathrm{C}$.

An important question then arises as to the species formed on $\mathrm{TiO}_{2}$ in the intermediate state. To analyze this, the mass spectra of the intermediates extracted at $200^{\circ} \mathrm{C}$ were measured under vacuum at various temperatures. The mass spectra for the fraction collected in the range between 100 and $400{ }^{\circ} \mathrm{C}$ are found to include only $\mathrm{H}_{2} \mathrm{O}, \mathrm{CO}$, and $\mathrm{CO}_{2}$, whereas the fragments derived from benzene begin to gradually appear above $400{ }^{\circ} \mathrm{C}$. Figure 10 shows the mass spectrum of the fraction collected at $480{ }^{\circ} \mathrm{C}$ for $30 \mathrm{~min}$. The fragments derived from benzene are clearly recognized at mass numbers of approximately 78, 51, and 39 in addition to 


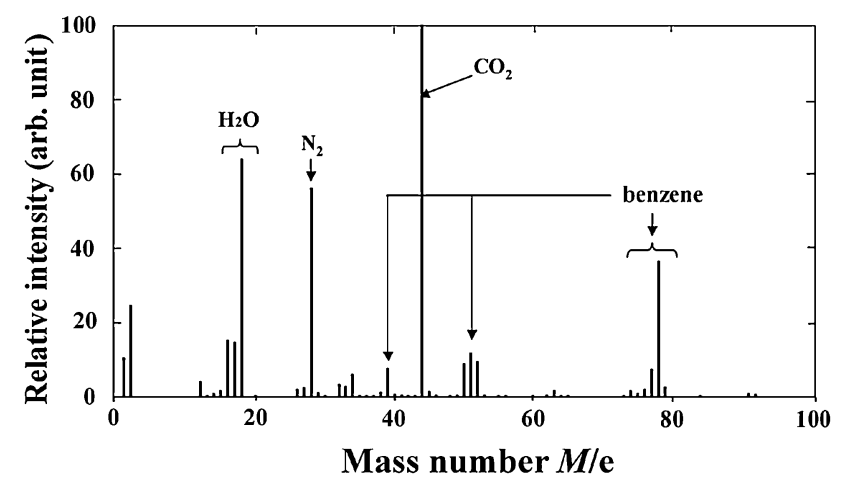

Fig. 10. Mass spectrum of desorbed species of benzene/ST01 powders sampled at $200^{\circ} \mathrm{C}$ for fraction collected at $480^{\circ} \mathrm{C}$ for $30 \mathrm{~min}$.

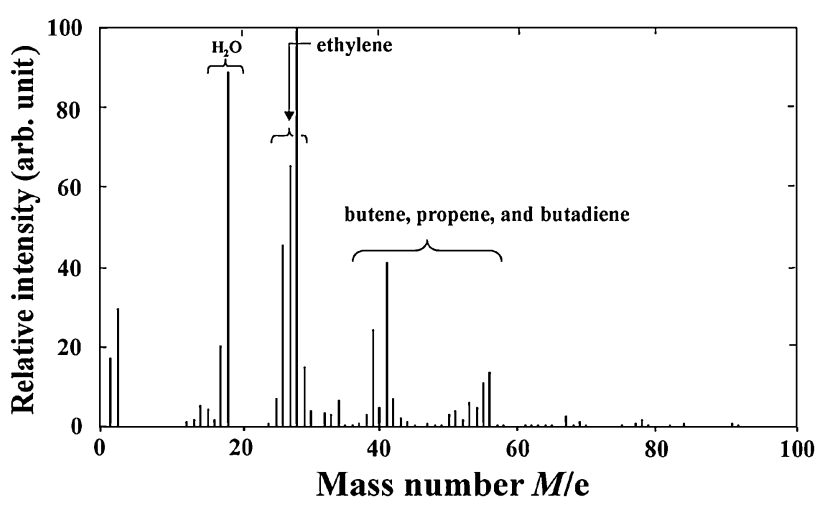

Fig. 11. Mass spectrum of desorbed species of benzene/ST01 powders sampled at $350^{\circ} \mathrm{C}$ for fraction collected in temperature range of $280-$ $380^{\circ} \mathrm{C}$. The experiment was carried out in a mixture of $\mathrm{N}_{2}$ and $\mathrm{O}_{2}$ (ratio: $\left.\mathrm{N}_{2} / \mathrm{O}_{2}=9 / 1\right)$.

the peaks of $\mathrm{H}_{2} \mathrm{O}, \mathrm{CO}$, and $\mathrm{CO}_{2}$. This clearly indicates that benzene (or only a slightly decomposed benzene) is firmly adsorbed on the surface of $\mathrm{TiO}_{2}$ and desorbed only above about $400{ }^{\circ} \mathrm{C}$.

\subsection{Elementary reaction in decomposition of benzene}

As shown in Fig. 5, no decomposition of benzene occurs in $\mathrm{N}_{2}$. In other words, the presence of oxygen is indispensable for the complete decomposition of benzene. This fact prompted us to believe that we can deaccelerate the reaction rate under oxygen-deficient conditions with an excess of $\mathrm{N}_{2}$ so as to identify the intermedidates of benzene. This experiment was carried out in a mixture of $\mathrm{N}_{2}$ and $\mathrm{O}_{2}$ (ratio: $\mathrm{N}_{2} / \mathrm{O}_{2}=9 / 1$ ) and the intermediates were sampled at various temperatures. Among these, the intermediate sampled at $350^{\circ} \mathrm{C}$ is found to include decomposition products. Figure 11 shows the mass spectra measured for the fraction collected in the temperature range between 280 and $380^{\circ} \mathrm{C}$. We observed a series of fragments composed of ethylene, butane, propene, and butadiene. These results suggest that benzene is completely decomposed into $\mathrm{H}_{2} \mathrm{O}$ and $\mathrm{CO}_{2}$ via ethylene, butane, propene, and butadiene.

\subsection{Decomposition of PM as monitored using Raman, ESR, and DSC spectra}

Since the decomposition of PM is supposed to occur at the "solid (PM)/solid $\left(\mathrm{TiO}_{2}\right)$ " interface, it is crucial to increase

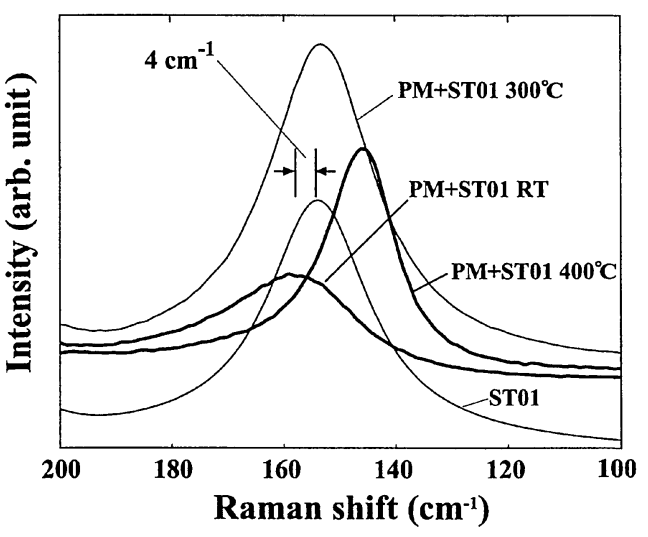

(a)

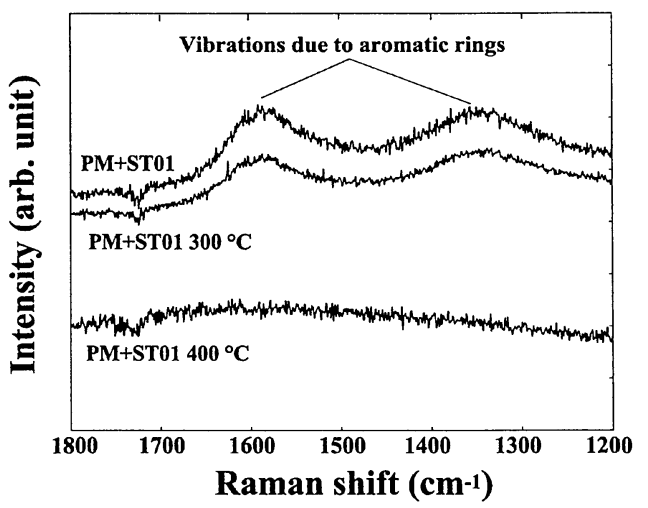

(b)

Fig. 12. (a) Peak shifts of Raman spectrum of $E_{\mathrm{g}}$ mode at approximately $150 \mathrm{~cm}^{-1}$ and (b) Raman spectra showing two bands due to aromatic rings for sample 1 (i.e., a mixture of PM and ST01) heated in air at various temperatures.

the contact frequency between $\mathrm{TiO}_{2}$ and $\mathrm{PM}$ and also to maintain the contact time as long as possible.

Figure 12(a) shows the Raman spectra of the $E_{\mathrm{g}}$ mode for sample 1 (i.e., a mixture of PM and ST01: see \$2.4) heated at various temperatures, using ST01 as the reference. Even at room temperature, a small peak shift of about $4 \mathrm{~cm}^{-1}$ toward higher wavenumbers is observed. Then, a reverse peak shift toward lower wavenumbers is recognized when heated at $300^{\circ} \mathrm{C}$ and the shift is even more enhanced at $400{ }^{\circ} \mathrm{C}$. Figure 12(b) shows the Raman spectra in the range between 1200 and $1800 \mathrm{~cm}^{-1}$. Two characteristic bands due to aromatic rings appear at approximately 1350 and $1600 \mathrm{~cm}^{-1}$ at room temperature and these bands remain even at $300^{\circ} \mathrm{C}$. Then, these bands disappear completely at $400^{\circ} \mathrm{C}$. In parallel, ESR measurements were also carried out on the following samples as a function of temperature: PM and sample 1. Figures 13(a) and 13(b) show the difference in the spectra of PM species, where the ESR signal of ST01 is subtracted from that of $\mathrm{PM}$ or sample 1 . No change is recognized in $\mathrm{PM}$ up to $100^{\circ} \mathrm{C}$. Then, the signal begins to weaken above $200^{\circ} \mathrm{C}$. On the other hand, in sample 1 , we observed a slight reduction in intensity even at $100^{\circ} \mathrm{C}$ and then the signal disappears completely at $200^{\circ} \mathrm{C}$. This result clearly indicates that the presence of $\mathrm{TiO}_{2}$ is, to some extent, effective in decomposing PM. This is further confirmed by a comparison experiment based on $\mathrm{CR} 80$ (i.e., inert $\mathrm{TiO}_{2}$ ) in place of ST01 that gives no effect. However, the color of 
(a)

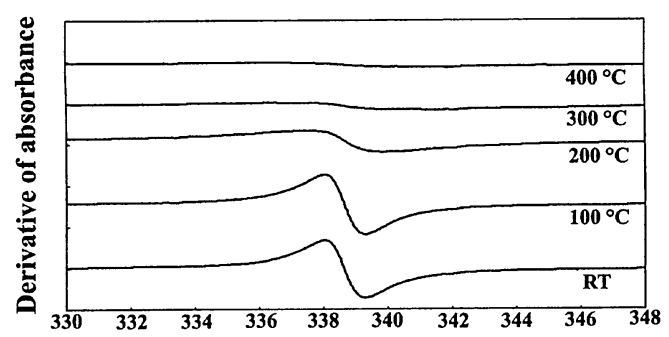

Magnetic field (mT)

(b)

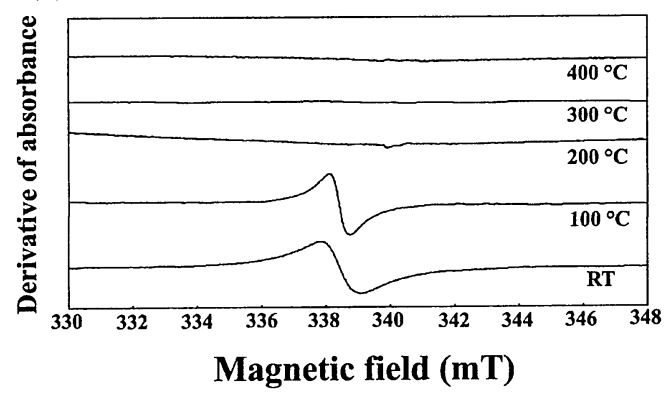

Fig. 13. (a) ESR spectra at various temperatures: (a) PM and (b) sample 1 (i.e., mixture of PM and ST01).

sample 1 (initially gray) is not yet entirely white (ST01), suggesting that the PM decomposition is still incomplete.

Then, sample 2 (i.e., pressed sample of sample 1) was tested, which provides better contacts between PM and ST01 during the decomposition. Figure 14 shows the DSC curves of samples 1 and 2. The shadowed area corresponds to the difference in exothermic energy that amounts to $27.7 \mathrm{~J} / \mathrm{g}$. This indicates that the press effect is significant for the PM decomposition. Sample 2, however, is not entirely white after DSC. Therefore, further trial was made to heat sample 1 under a pressure of about $280 \mathrm{~N} / \mathrm{m}^{2}$ at $350{ }^{\circ} \mathrm{C}$ for $5 \mathrm{~min}$ ("hot press"). Then, the gray color disappeared completely, indicating that PM was completely decomposed.

The above results suggest that even PM can basically be decomposed into $\mathrm{H}_{2} \mathrm{O}$ and $\mathrm{CO}_{2}$, provided that the contact frequency between $\mathrm{PM}$ and $\mathrm{TiO}_{2}$ is high and that the contact time is sufficiently long while heating.

\section{Conclusions}

The complete decomposition of benzene, toluene, and

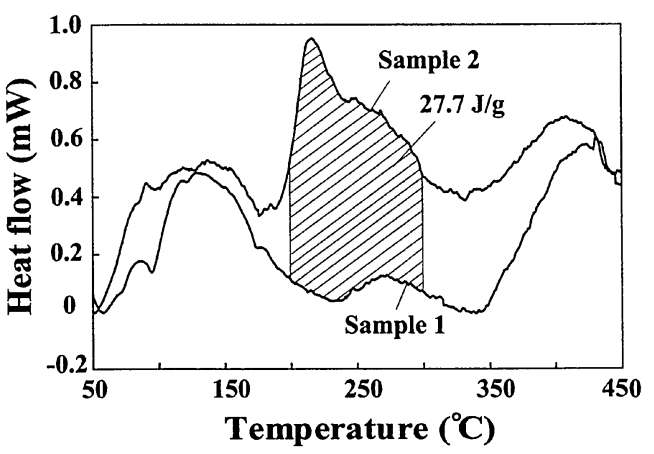

Fig. 14. DSC curves of sample 1 (i.e., a mixture of PM and ST01) and sample 2 (i.e., pressed sample of sample 1).

PM contained in the exhaust of diesel engines has been investigated. The conclusions can be summarized as follows.

1. Strong interactions are found between the adsorbate (benzene or toluene) and the adsorbent $\left(\mathrm{TiO}_{2}\right)$ as indicated by the appearance of brownish benzene/ ST01 or toluene/ST01 powders that are further associated with the formation of radicals. The present spontaneous adsorption of benzene or toluene on $\mathrm{TiO}_{2}$ is quite advantageous to their subsequent decomposition into $\mathrm{H}_{2} \mathrm{O}$ and $\mathrm{CO}_{2}$.

2. Benzene or toluene decomposes completely into $\mathrm{H}_{2} \mathrm{O}$ and $\mathrm{CO}_{2}$ at about $350-500{ }^{\circ} \mathrm{C}$. The elementary decomposition of benzene proceeds via ethylene, butane, propene, and butadiene.

3. PM is also found to completely decompose, provided that the contact frequency between $\mathrm{PM}$ and $\mathrm{TiO}_{2}$ is high and that the contact time is sufficiently long while heating.

1) J. Mizuguchi: J. Electrochem. Soc. 148 (2001) J55.

2) J. Mizuguchi and T. Shinbara: J. Appl. Phys. 96 (2004) 3514.

3) T. Shinbara, T. Makino, K. Matsumoto, and J. Mizuguchi: J. Appl. Phys. 98 (2005) 044909.

4) C. Kittel: Introduction to Solid State Physics (Wiley, New York, 1986) 6th ed.

5) K. Hauffe and S. R. Morrison: Adsorption (Water de Gruyter, Berlin and New York, 1974).

6) C. G. Scott and C. E. Reed: Surface Physics of Phosphors and Semiconductors (Academic Press, London, 1975) Chap. 4.

7) U. Balachandran and N. G. Eror: J. Solid Sate Chem. 42 (1982) 276.

8) T. Ohsaka, F. Izumi, and Y. Fujiki: J. Raman Spectrosc. 7 (1978) 321.

9) N. Krishnamurthy and T. M. Haridasan: Indian J. Pure Appl. Phys. 17 (1979) 67. 